\title{
Incorporating Transportation Mode Decisions into Production-Shipping Planning: Considering Shipping Consolidation
}

\author{
Qian Huang \\ Waseda Research Institute for Science and Engineering, \\ Waseda University, Japan \\ E-mail: huangqian365@gmail.com (Corresponding Author) \\ Shunichi Ohmori \\ Department of Business Design and Management, \\ Waseda University, Japan \\ E-mail: ohmori0406@aoni.waseda.jp \\ Kazuho Yoshimoto \\ Department of Industrial and Management Systems Engineering, \\ Waseda University, Japan \\ E-mail: kazuho@waseda.jp
}

\begin{abstract}
This study develops a global production-shipping planning model that incorporates a decision on transportation mode after considering the cost function of different transportation modes from the shipper's point of view. We propose tramp shipping, liner shipping, and a mixed mode to select the optimal shipping mode, considering transshipment and consolidation to exploit economies of scale under a given network. We present mathematical formulations of tramp, liner and mixed modes and apply a piecewise approximation technique with mixed-linear integer programming to linearly approximate the concave minimization problem and efficiently solve it using an off-the-shelf solver. In order to verify the effectiveness of the proposed modes, the three modes are compared and discussed in numerical examples. The advantages and disadvantage of the three modes are discussed under different situations. The result is a decision aided system to support production-shipping planning in selecting the optimal transportation mode.
\end{abstract}

Keywords: production-shipping planning, transportation mode, consolidation, optimization, economies of scale

\section{INTRODUCTION}

After centuries of technological progress and advances in international cooperation, the world is more connected than ever. Manufacturers are operating on an international scale, and products flow freely between markets across the world. Since material costs and labor costs are different among countries, it is important to consider the optimal production location for each product. Also, factors of inbound tariffs, local taxes, and country risks are important parameters in global production planning. Because of the fundamental link between globalization and transportation, transportation is a key component of supply chain logistics. When the scale of global production network grows, the role of transportation, typically marine transportation becomes more significant. With, multiple global suppliers, customers all over the world, and long transportation distances result in complex production-shipping models.

The mode of marine transportation, whether tramp, industrial, or liner, significantly impacts the structure and efficiency of transportation planning (Christiansen et al. 2013). Ship routing and scheduling decisions in industrial and tramp operations are very similar; therefore, they will be discussed together. The mainstay of industrial and tramp shipping is bulk cargo that is shipped in large quantities, such as crude oil, coal, iron ore, grain, oil products, and chemicals. The shipments do not have fixed routes or predetermined schedules of departure. Most bulk commodities are shipped in full shiploads from their loading port to their destination port. This is similar to a taxicab service. Liner vessels follow a fixed route according to a published schedule - similar to a public bus service. Although the frequency of sailings may change seasonally, the routes themselves may not change for several years.

Typically, a shipping service offers volume, or quantity, discounts to their clients to encourage demand for larger, more profitable shipments. Figure 1 presents how economies of scale are considered in each transportation mode. In the tramp shipping mode, a shipper subcontracts the transportation from origin to destination over a specified period and pays a fixed fee to the subcontractor. The shipper's cost is proportional to the shipping volume. This can be modeled as a fixed and variable cost function as described in Figure 1(a). In a liner shipping mode, most commodities are shipped in less-than-full-shiploads. The shipment fee is predetermined by the shipping company, which considers volume discounts. The cost function can be 
modeled as a concave function as shown in Figure 1(b). Notably, in prior research on production-distribution systems, transportation cost is calculated by the unit cost times the distribution volume. In other words, the unit-price of distribution costs is constant whether the volume is high or low.

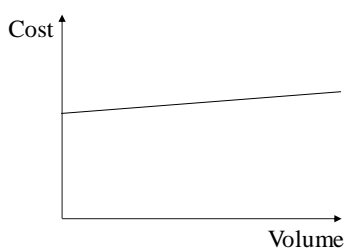

(a) Fixed and variable cost function for tramp shipping mode

Figure 1. Cost function in tramp and liner transportation modes



(a) Tramp

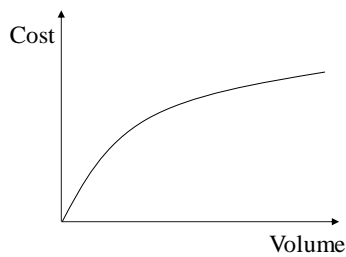

(b) Concave cost function for liner shipping mode different transportation modes. We propose a mixed model of tramp and liner shipping in this study to choose the correct shipping mode after considering transshipment and consolidation exploiting economies of scale under a given network. We present mathematical formulations of three models: tramp, linear, and a mixed model. We apply the piecewise approximation technique to linearly approximate the concave minimization problem to a mixed-linear integer programming to efficiently make good decisions using an off-the-shelf solver. To verify their effectiveness, the three models are compared and discussed in a numerical example.

The remainder of this paper is organized as follows: Section 2 includes a review of the relevant literature on production-distribution problems, Section 3 describes the research problem and presents the model. Section 4 discusses the compared models and the results of the numerical experiments. Finally, Section 5 summarizes the conclusions.

\section{LITERATURE REVIEW}

In this section, we review related research on topics like ship routing and scheduling problems, multi-commodity network flow problems, and production routing problem. Ship routing and scheduling and their related problems have been a popular topic in operations research. The increase in of papers indicate that the need for efficient design and operation of the world fleet increases with globalization. See Ronen (1993) and Christiansen et al. (2013) for a review. There are two particular research streams on transportation modes: those on liner shipping and those on tramp shipping.

In liner shipping, one major research area is problems in network design. There is a vast amount of research on problems in transshipment at hub ports (Hsu and Hsieh 2007, Karlaftis et al. 2009), hub locations (Gelareh et al. 2010), empty container repositioning (Meng and Wang 2011), and fleet allocation (Reinhardt and Pisinger 2012). Another important planning problem in liner shipping is fleet deployment, which is the tactical planning problem of assigning ships to liner routes (Powell and Perakis 1997 , Gelareh and Meng 2010). Lei et al. (2008) studied various degrees of collaboration among container shipping companies. Meng and Wang (2011) developed a container flow simulation model for intermodal freight transportation systems. Boros et al. (2008) studied the problem of determining the optimal cycle time. Lagoudis et al. (2010) presented a model to be used to determine optimal vessel and container fleet size. $\mathrm{Ng}$ and Kee (2008) undertook an investigation to simulate the optimal containership sizes from the perspective of ship operators.

In tramp shipping, the major research vein is problems in routing cargo and scheduling. This includes determining the optimal set of routes for a fleet of ships to carry a particular set of cargo. Jetlund and Karimi (2004) presented a model for maximum-profit scheduling of a fleet of multiparcel tankers engaged in shipping bulk liquid chemicals. Korsvik et al. (2010) proposed tabu-search heuristics. Malliappi et al. (2011) offered a variable neighborhood search. Another, more tactical decision-making problem, is fleet size and composition, which studies how to manage a fleet over time, including decisions about how many ships to buy, sell, charter-in, and charter-out, as well as the timing of these activities in order to meet demand (Hoff et al. 2010,

Zeng and Yang 2007, Fagerholt et al. 2010, Álvarez et al. transportation mode, considering the cost function of 
2011). Recent studies have incorporated inventory decisions into routing, a process called maritime inventory routing, in which an actor has the responsibility for inventory management at one or both ends of the maritime transportation legs and for the ships' routing and scheduling (Sherali and Al-Yakoob 2006a, Sherali and Al-Yakoob 2006b, Christiansen et al. 2007, Christiansen and Fagerholt 2010, Andersson et al. 2010, Song and Furman 2013, Zhang et al. 2018, Papageorgiou 2018). Recently, speed optimization for shipping routes has attracted attention because sailing speed determines fuel consumption, which affects a profit maximization approach (Gatica and Miranda 2011, Wen et al. 2017, Lakhal 2018). Wang et al. (2019) presented a model for green tramp shipping routing and scheduling to examine how potential measures for $\mathrm{CO}_{2}$ emission reduction could impact operational decisions and the economic and environmental consequences.

Transportation planning for tramp and liner shipments is very similar to the well-known multi-commodity network flow problem. See Mahey (2017) for a recent review. There are several studies that examine the exact concave minimization problem (Tuy 1964, Zangwill 1968, Erickson, Monma, and Veinott 1987, Ward 1999). An exhaustive search of all extreme points would provide an optimal flow, since a concave function achieves its minimum at an extreme point of the convex feasible region. However, such an approach is impractical for all but the simplest of problems. The fixed-charge network design problem has been also extensively studied in various applications: telecommunications, logistics, and transportation (Magnanti and Wong 1984, Balakrishnan, Magnanti, and Mirchandani 1997, Teo and Shu 2004, Shu 2010, Diabat Battaia and Nazzal 2015, Vanteddu and Nicholls 2019). Piecewise linearization is a popular technique to approximately minimize the concave cost function (Balakrishnan and Graves 1989, Amiry and Pirkul 1997, Chan, Muriel, and Simchi-Levi 1999, Kim and Paradalos 2000, Muriel and Munshi 2002).

Another related line of research is on the Production Routing Problem (PRP), which combines lot sizing and vehicle routing. Solving the PRP should jointly optimize production, inventory, distribution, and routing decisions and thus, it is a generalization of the inventory routing problem. The benefits of coordination in the PRP were first discussed by Chandra (1993) and Chandra and Fisher (1994). Although there are some variants in the model, such as number of plants, number of products, the existence of production/inventory capacity, inventory policies, and size of the fleet, the main focus of this problem is to develop a solution method, due to the complexity of the problem. Boudia et al. (2007) proposed GRASP-based heuristics, Boudia et al. (2007) applied a memetic algorithm, Armentano et al. (2011) applied tabu-search based heuristics, and Adulyasak (2014) proposed ALNS. Fumero and Vercellis (1999) and Solyalı and Süral (2009) developed a Lagrangian relaxation approach to obtain lower bounds, based on a formula for multi-commodity flow. Ruokokoski et al. (2010) and Archetti et al. (2007) employed a branchand-cut approach.

This paper makes the following contributions to the abovementioned research streams.

1) There is a substantial amount of research on ship routing and scheduling problems for liner and tramp shipment modes. These papers, however, plan and optimize shipping and routing from the carrier's point of view under a given transportation mode. They do not compare the linear and tramp shipping modes explicitly from the shipper's point of view. This research discusses the advantage and disadvantage of shipping modes and examines transportation modes under different situations, which is of great interest in practice.

2) While a typical shipment routing and scheduling model assume to serve a given set of cargo from an origin to a destination, our model includes productions decisions in the model; thus, there is flexibility in selecting the plant that will fulfill the demand. This may impact the choice of transportation, because there may be more opportunities to consolidate shipments. None of the prior research has considered this issue.

3) We propose a model integrating both linear and tramp shipping modes. As with all matters of logistics, a onesize-fits-all approach ends up in failure in some situations. Tramp shipping becomes more appropriate as the shipping volume increases, and vice versa. The proposed mixed model chooses the correct shipping mode considering transshipment and consolidation to exploit economies of scale in given network. We apply a piecewise approximation technique with mixed-linear integer programming to linearly approximate the concave minimization problem and efficiently solve the problem using an off-the-shelf solver.

4) We present a practical case study that is motivated from a real-world example. We discuss the difference in production and transportation decisions among three transportation modes (tramp, liner, and mixed mode). Sensitivity analysis helps to show how the parameter settings in the cost function influence the choice of transportation modes.

\section{PROPOSED MODEL}

The following section describes the modeling framework. We present three modeling frameworks, i.e., a liner shipping model, a tramp shipping model, and a mixed shipping model. Section 3.1 presents a summary of the notation, Section 3.2 presents the liner shipping model, Section 3.3 presents the tramp shipping model, and Section 3.4 presents a mixed shipping model.

\subsection{Notation and Assumptions}

We let $V=\{i \mid 1, \cdots, n\}$ be a set of nodes. $V$ is composed of a set of plant nodes $V_{S}=\left\{i \mid 1, \cdots, n_{S}\right\}$ and a set of market nodes $V_{C}=\left\{i \mid n_{S}+1, \cdots, n_{S}+n_{C}\right\}$ and $n=$ $n_{S}+n_{C}$. Let $E=\{(i, j) \mid i, j \in V\}$ be a set of arcs, $E_{T} \subseteq$ $E=\{(i, j) \mid i, j \in V\}$ be a set of arcs for potential tramp shipment and $E_{L} \subseteq E$ be a set of arcs for liner shipments. We assume that there are arcs for all plant-market pairs in the potential tramp shipment graph $G_{T}\left(V, E_{T}\right)$. In the liner shipment graph $G_{L}\left(V, E_{L}\right)$, there is not always direct arc for all plant-market pairs. Also, there are some arcs between plants and between markets. Figure 3 illustrates an example of $G_{T}\left(V, E_{T}\right)$ and $G_{L}\left(V, E_{L}\right)$ with $n_{S}=2, n_{C}=3$. To represent flow conservation at each node, we let $P_{e i}$ be the incidence matrix, defined as 


$$
P_{e i}=\left\{\begin{array}{cc}
-1 & \text { if arc } e \text { points to node } i \\
1 & \text { if } \operatorname{arc} e \text { points from node } i \\
0 & \text { otherwise. }
\end{array}\right.
$$

There is only one product type. We assume that the unit production costs for each plant are not very different, and thus, we do not include the production cost in the objective function. We assume that each plant is at production capacity. We do not assume the capacity for each arc.

We let $x_{e}$ be the shipment volume of arc $e$. Each plant node $i \in V_{S}$ has its production capacity $q_{i}$. Then, $y_{i}$ is production volume of node $i$ and does not exceed its capacity. Each market node $i \in V_{C}$ has demand $d_{i}$ and the total shipped volume for demand $i$ must be equals to $d_{i}$.

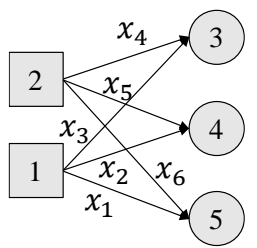

(a) $G_{T}\left(V, E_{T}\right)$



(b) $G_{L}\left(V, E_{L}\right)$
Figure 3. An example illustrating the potential tramp shipment graph $G_{T}\left(V, E_{T}\right)$ and liner shipment graph $G_{L}\left(V, E_{L}\right)$ with $n_{S}=$ $2, n_{C}=3$

\subsection{Tramp Shipping Model}

We let $z_{e}$ be the binary variable to take one if the arc $e$ is opened for subcontract and zero otherwise. There is fixed cost $f_{e}$ and variable cost $c_{e}^{T}$ that is proportional to the shipment volume. The cost for edge $e$ is formulated by $f_{e} z_{e}+c_{e}^{T} x_{e}$.

The trump shipping model has the following input and decision variables.

- Input

- $f_{e}$ : Fixed shipping cost for arc $e$

- $c_{e}^{T}$ : Unit variable shipping cost for arc $e$

- $d_{i}$ : Demand of market $e$

- $q_{i}$ : Shipping capacity of plant $i$

- $P_{e i}$ : Incidence matrix

- $Q$ : very large number

- Decision variable

- $x_{e}$ : Shipping volume for $\operatorname{arc} e$

- $y_{i}$ : Production volume for plant $i$

- $z_{e}$ : Binary variable to take one if arc $e$ is opened

The formulation is as follows:

minimize $\sum_{e \in E_{T}}\left(f_{e} z_{e}+c_{e}^{T} x_{e}\right)$

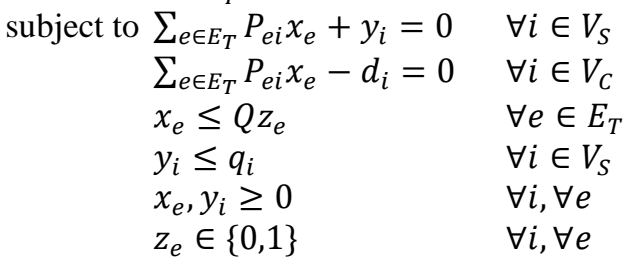

Objective function (1a) is total shipping cost. Constraints (1b) requires the flow conservation for the plant node. Constraints (1c) requires the flow conservation for the market node. Constraints (1d) requires that the total shipping volume for each arc can be positive only if the arc is opened. Constraints (1e) requires the total shipping volume from each plant is less than or equals to its capacity. Constraints (1f) requires that shipping and production volume is nonnegative. Constraints $(1 \mathrm{~g})$ requires that $z_{e}$ should be binary variable.

\subsection{Liner Shipping Model}

There is no fixed cost. Typically, liner shipping service offer volume, or quantity, discounts to their clients to encourage demand for larger, more profitable shipments. The cost can be modeled as the concave cost function $c_{e}^{L} \sqrt{x_{e}}$.

The liner shipping model has the following input and decision variables.

- Input

- $\quad c_{e}^{L}$ : Unit shipping cost from supplier $i$ to market $j$

- $d_{i}$ : Demand of market $i$

- $q_{i}$ : Shipping capacity of supplier $i$

- $P_{e i}:$ Incidence matrix

- Decision variable

- $x_{e}$ : Shipping volume for arc $e$

- $y_{i}$ : Production volume for supplier $i$

The formulation is as follows:

Minimize $\quad \sum_{e \in E_{L}} c_{e}^{L} \sqrt{x_{e}}$

subject to $\quad \sum_{e \in E_{L}} P_{e i} x_{e}+y_{i}=0 \quad \forall i \in V_{S}$

$\sum_{e \in E_{L}} P_{e i} x_{e}-d_{i}=0 \quad \forall i \in V_{C}$

$$
y_{i} \leq q_{i}
$$

$\forall i \in V_{S}$

$x_{e}, y_{i} \geq 0$

$\forall i, \forall e$

The objective function (2a) is the total shipping cost. Constraint (2b) sets the flow conservation for the plant node. Constraint (2c) sets the flow conservation for the market node. Constraint $(2 \mathrm{~d})$ requires that the total shipping volume to each market equals the requested demand. Constraints (2e) requires that shipping and production volume is nonnegative.

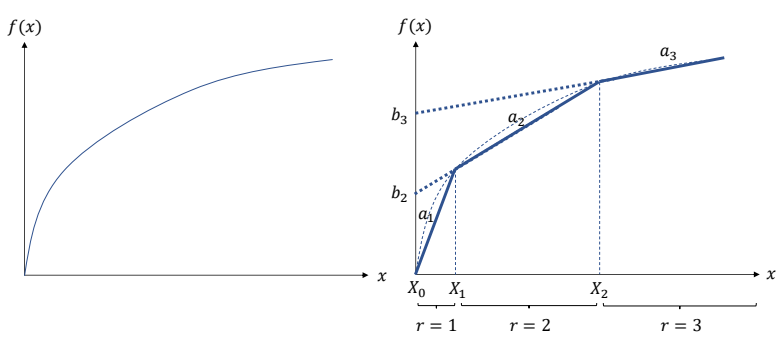

Figure 4. Piecewise linearization of concave cost function

Because problem (2) is a nonlinear concave minimization problem, it is difficult to solve. We use the piecewise linearization approximation method to approximate problem (2) to a mixed-linear programming problem.

To simply, we drop the subscript $e$ and let $f(x)$ be the concave function to minimize. $R$ denotes the number of linear pieces in the function $f(x)$, and $a_{r}, b_{r}$ is the slope and offset in section $r$. Figure 4 illustrates how the concave function is supported by the linear functions with $R=3$. We let $w_{r}$ denote the binary variable to indicate that if section $r$ is selected, $X_{r}$ is the upper bound of section $r$. Also, $x_{r}$ is a dummy variable to take $x$ if the section $r$ is selected and 0 otherwise as follows: 


$$
x_{r}= \begin{cases}x, & \text { if } w_{r}=1 \\ 0, & \text { otherwise }\end{cases}
$$

The nonlinear optimization problem:

$\begin{array}{ll}\text { Minimize } & f(x) \\ \text { subject to } & x \geq 0\end{array}$

can be approximated via a mixed-integer linear programming problem as follows:

$\begin{array}{ll}\text { Minimize } & \sum_{r=1}^{R} a_{r} x_{r}+b_{r} w_{r} \\ \text { subject to } & \sum_{r=1}^{R} w_{r} \leq 1 \\ & \sum_{r=1}^{R} x_{r}=x \\ & X_{r-1} w_{r} \leq x_{r} \leq X_{r} w_{r} \\ & w_{r} \in\{0,1\}\end{array}$

Using this approximation, we have the following formulation:

$$
\begin{aligned}
& \text { Minimize } \sum_{e=1}^{m_{T}} \sum_{r=1}^{R} c_{e}^{L}\left(a_{e r} x_{e r}+b_{e r} w_{e r}\right) \\
& \text { subject to } \sum_{r=1}^{R} w_{e r} \leq 1 \quad \forall e \in E_{L}, \forall r \\
& \sum_{r=1}^{R} x_{e r}=x_{e} \quad \forall e \in E_{L} \\
& X_{r-1} w_{e r} \leq x_{e r} \leq X_{r} w_{e r} \forall e \in E_{L}, \forall r \\
& w_{e r} \in\{0,1\} \quad \forall e \in E_{L}, \forall r \\
& \text { (2b) - (2e) }
\end{aligned}
$$

where $x_{e r}$ is shipping volume for arc $e$ for section $r$, $w_{e r}$ is binary variable to indicate if shipping volume for arc $e$ for section $r$ is in the section $r, a_{e r}, b_{e r}$ is the slope and offset for arc $e$ in section $r$, respectively. The problem is transformed into a mixed-linear integer programming problem, and thus can be solved very efficiently by an offthe-shelf solver, i.e., Gurobi optimizer or CPLEX.

\subsection{Mixed Shipping Model}

We present a model integrating both linear and tramp shipping modes. The variables $x_{e}^{T}$ and $x_{e}^{L}$ are the shipping volume for arc $e$ via tramp and liner shipping, respectively. The formulation of the mixed shipping model is presented as follows:

$$
\begin{aligned}
& \text { Minimize } \sum_{e \in E_{T}}\left(f_{e} z_{e}+c_{e}^{T} x_{e}^{T}\right)+\sum_{e \in E_{L}} c_{e}^{L} \sqrt{x_{e}^{L}} \\
& \text { subject to } \sum_{e \in E} P_{e i}\left(x_{e}^{T}+x_{e}^{L}\right)+y_{i}=0 \quad \forall i \in V_{S}(4 \mathrm{~b}) \\
& \sum_{e \in E} P_{e i}\left(x_{e}^{T}+x_{e}^{L}\right)-d_{i}=0 \quad \forall i \in V_{C}(4 \mathrm{c}) \\
& x_{e} \leq Q z_{e} \\
& y_{i} \leq q_{i} \\
& x_{e}, y_{i} \geq 0 \\
& z_{e} \in\{0,1\} \\
& \forall e \in E_{T}(4 \mathrm{~d}) \\
& \forall i \in V_{S}(4 \mathrm{e}) \\
& \forall i, \forall e \quad(4 \mathrm{f}) \\
& \forall i, \forall e \quad(4 \mathrm{~g})
\end{aligned}
$$

The objective function (4a) is the total shipping cost. Constraints (4b) set the flow conservation for the plant node. Constraints (4c) set the flow conservation for the market node. Constraints (4d) requires that the total shipping volume for each arc can be positive if the arc is opened. Constraints (4e) mean the total shipping volume from each supplier is less than or equal to its capacity. Constraint (4f) requires that shipping and production volume are nonnegative. Finally, Constraint $(4 \mathrm{~g})$ requires that $z_{e}$ is a binary variable. The proposed mixed model chooses the correct shipping mode considering transshipment and consolidation to exploit the economies of scale under given network.

\section{NUMERICAL EXAMPLES}

To demonstrate the applicability of the proposed model, in this section, numerical experiments are carried out on three models of global production networks: a productiontramp shipping model, a production-liner shipping model and a production-mixed shipping mode model.

\subsection{Test Problem Description}

We consider the transportation network motivated by a global manufacturing company. The network consisting of five plants and twelve markets. The five plants are in Osaka, Shanghai, Hochimin, Bangkok, and Port Klang. The twelve markets are in Tokyo, Pusan, Qingdao, Hong Kong, Yangon, Mundra, Chennai, Singapore, Jakarta, Manila, Sydney, and Auckland. The transportation networks are tramp and liner shipping, tramp shipping is connecting each plant and market, liner shipping is via multiple plant and market. We picked ten liners which often travel around the five plants and twelve markets using the data of a liner shipping company. The shipping network are described in Figure 5 and Figure 6, respectively. The plants are represented by boxes and the markets are represented by circles. The flow of a commodity via tramp shipping is represented by an arrow with a solid line, and the flow of a commodity via liner shipping is represented by an arrow with a dashed line.



Figure 5. Tramp Shipping Network

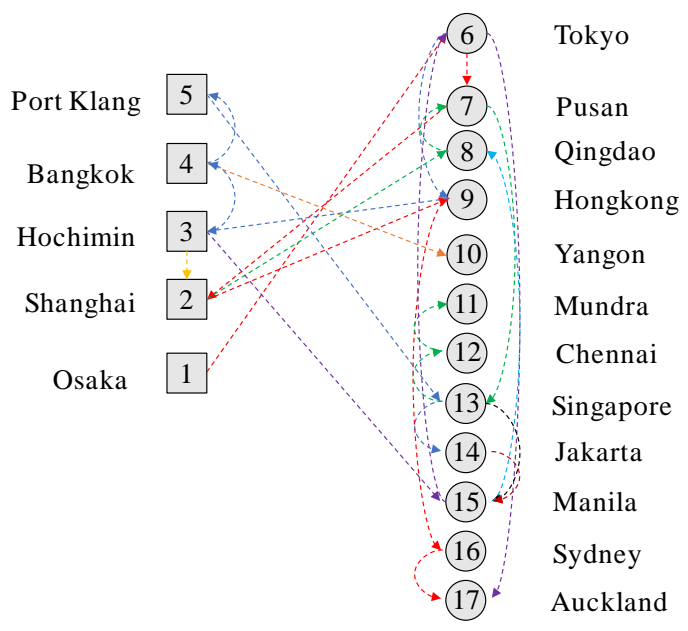

Figure 6. Liner Shipping Network 
The operating horizon is one year, and the planning cycle is one month. The unit production cost for each plant are not very different because the product is mature and the different plants have similar production skills. Along with global sourcing, the gap that distinguishes material costs is narrower than before; materials of an approximate price can be supplied to each plant all over the world. Thus, production planning considering transportation planning is particularly important

The following describes the data required by the models to set values. We generate production capacity and the customer demands of container unit base in random. The production capacity of each plant is given in Table 1. The demand for each market is given in Table 2. The total production capacity is equal to 250 units, which is greater than the total customer demand of 182 units.

The number of sections, $R=10$ and $X_{r}$ is $10 r$. To set the $c_{e}^{T}, f_{e}$ and $c_{e}^{L}$, we set the unit traveling cost $c_{e}$ as an intermediate parameter presented in Table 3 calculated from the data of a liner shipping company. We set $c_{e}^{L}=\sqrt{c_{e}}$ and the liner cost function can be formed as $\sqrt{c_{e} x_{e}}=c_{e}^{L} \sqrt{x_{e}}$.
We let maximal cost $C_{e}=c_{e}^{L} \sqrt{X_{R}}$. We set $f_{e}=\alpha C$ and $c_{e}^{T}=\left(\beta C-f_{e}\right) / X_{R} \quad$ with $\quad \alpha=0.1, \beta=0.2$. This relationship of tramp shipping costs and liner shipping costs are illustrated in Figure 7. The unit cost of tramp shipping and liner shipping is dependent of the amount transported.

Table 1. Production capacity (units/month)

\begin{tabular}{|c|c|c|}
\hline Production site & Name & Production capacity \\
\hline 1 & Osaka & 50 \\
\hline 2 & Shanghai & 70 \\
\hline 3 & Hochimin & 40 \\
\hline 4 & Bangkok & 60 \\
\hline 5 & Port Klang & 30 \\
\hline
\end{tabular}

Table 2. The customer demands (units/month)

\begin{tabular}{|c|c|c|c|c|c|}
\hline $\begin{array}{c}\text { Market } \\
\text { site }\end{array}$ & Name & Demand & $\begin{array}{c}\text { Market } \\
\text { site }\end{array}$ & Name & Demand \\
\hline 6 & Tokyo & 21 & 12 & Chennai & 12 \\
\hline 7 & Pusan & 16 & 13 & Singapore & 21 \\
\hline 8 & Qingdao & 16 & 14 & Jakarta & 16 \\
\hline 9 & $\begin{array}{c}\text { Hong } \\
\text { Kong }\end{array}$ & 21 & 15 & Manila & 12 \\
\hline 10 & Yangon & 12 & 16 & Sydney & 16 \\
\hline 11 & Mundra & 12 & 17 & Auckland & 8 \\
\hline
\end{tabular}

Table 3. The unit traveling cost of liner shipping $(\times \$ 100)$

\begin{tabular}{|c|c|c|c|c|c|c|c|c|c|c|c|c|c|c|c|}
\hline $\boldsymbol{e}$ & $i$ & $j$ & $c_{e}$ & $\boldsymbol{e}$ & $i$ & $j$ & $c_{e}$ & $\boldsymbol{e}$ & $i$ & $j$ & $c_{e}$ & $\boldsymbol{e}$ & $i$ & $\boldsymbol{j}$ & $c_{e}$ \\
\hline 1 & 1 & 6 & 10 & 21 & 2 & 14 & 50 & 41 & 4 & 10 & 10 & 61 & 6 & 7 & 10 \\
\hline 2 & 1 & 7 & 20 & 22 & 2 & 15 & 30 & 42 & 4 & 11 & 45 & 62 & 7 & 2 & 10 \\
\hline 3 & 1 & 8 & 30 & 23 & 2 & 16 & 50 & 43 & 4 & 12 & 35 & 63 & 9 & 16 & 40 \\
\hline 4 & 1 & 9 & 30 & 24 & 2 & 17 & 60 & 44 & 4 & 13 & 10 & 64 & 16 & 17 & 10 \\
\hline 5 & 1 & 10 & 60 & 25 & 3 & 6 & 45 & 45 & 4 & 14 & 20 & 65 & 6 & 9 & 35 \\
\hline 6 & 1 & 11 & 80 & 26 & 3 & 7 & 35 & 46 & 4 & 15 & 30 & 66 & 9 & 3 & 10 \\
\hline 7 & 1 & 12 & 70 & 27 & 3 & 8 & 30 & 47 & 4 & 16 & 50 & 67 & 3 & 4 & 10 \\
\hline 8 & 1 & 13 & 50 & 28 & 3 & 9 & 10 & 48 & 4 & 17 & 60 & 68 & 4 & 5 & 10 \\
\hline 9 & 1 & 14 & 50 & 29 & 3 & 10 & 20 & 49 & 5 & 6 & 35 & 69 & 5 & 13 & 10 \\
\hline 10 & 1 & 15 & 30 & 30 & 3 & 11 & 45 & 50 & 5 & 7 & 45 & 70 & 13 & 14 & 10 \\
\hline 11 & 1 & 16 & 90 & 31 & 3 & 12 & 35 & 51 & 5 & 8 & 35 & 71 & 8 & 7 & 10 \\
\hline 12 & 1 & 17 & 70 & 32 & 3 & 13 & 20 & 52 & 5 & 9 & 30 & 72 & 7 & 13 & 25 \\
\hline 13 & 2 & 6 & 20 & 33 & 3 & 14 & 30 & 53 & 5 & 10 & 20 & 73 & 13 & 12 & 30 \\
\hline 14 & 2 & 7 & 10 & 34 & 3 & 15 & 35 & 54 & 5 & 11 & 35 & 74 & 12 & 11 & 30 \\
\hline 15 & 2 & 8 & 10 & 35 & 3 & 16 & 45 & 55 & 5 & 12 & 25 & 75 & 3 & 2 & 20 \\
\hline 16 & 2 & 9 & 10 & 36 & 3 & 17 & 55 & 56 & 5 & 13 & 10 & 76 & 15 & 6 & 30 \\
\hline 17 & 2 & 10 & 35 & 37 & 4 & 6 & 45 & 57 & 5 & 14 & 20 & 77 & 6 & 17 & 80 \\
\hline 18 & 2 & 11 & 60 & 38 & 4 & 7 & 40 & 58 & 5 & 15 & 30 & 78 & 13 & 15 & 10 \\
\hline 19 & 2 & 12 & 50 & 39 & 4 & 8 & 40 & 59 & 5 & 16 & 60 & 79 & 15 & 8 & 30 \\
\hline 20 & 2 & 13 & 40 & 40 & 4 & 9 & 20 & 60 & 5 & 17 & 70 & 80 & 14 & 15 & 30 \\
\hline
\end{tabular}




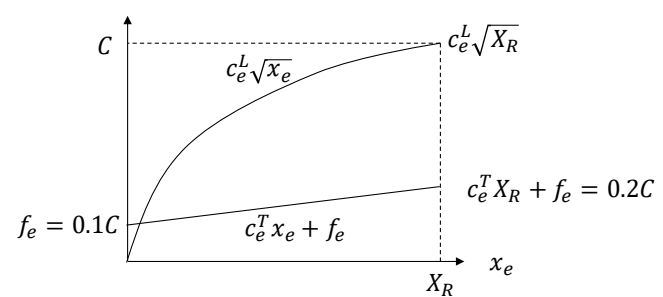

Figure 7. Example of tramp shipping and liner shipping cost function

We examine different scenarios of operation to demonstrate the effectiveness of proposed model. These scenarios are: (1) tramp shipping mode; (2) liner shipping mode; (3) mixed shipping mode.

The first scenario is tramp shipping mode, which typically occurs with the centralized strategy of global manufacturing. The second scenario is liner shipping mode, which typically occurs with the decentralized strategy of global manufacturing. The third scenario is mixed shipping mode.

The model described above is implemented in Gurobi optimizer run on the personal computer with Intel (R) Core (TM) i7-8700 CPU, 3.20GHz, 3.19GHz with $32.0 \mathrm{~GB}$ memory.

\subsection{Results of Numerical Experiments}

Table 4 and Table 5 shows the total costs and production allocation of each scenario respectively. Figure 8, Figure 9, and Figure 10 shows the supplying flows from plants to markets under liner and tramp shipping modes.

Table 4. Cost construction and total cost of each scenario ( $X$ $\$ 100)$

\begin{tabular}{|c|c|c|c|}
\hline Cost Item & Tramp & Liner & Mixed \\
\hline Fixed Cost & 53.7 & 0 & 26.0 \\
\hline Variable Cost & 5.9 & 61.7 & 20.7 \\
\hline Total Cost & 59.6 & 61.7 & 46.7 \\
\hline
\end{tabular}

Table 5. Production allocation of each scenario (units)

\begin{tabular}{|c|c|c|c|c|}
\hline Node & Name & Tramp & Liner & Mixed \\
\hline 1 & Osaka & 33 & 45 & 29 \\
\hline 2 & Shanghai & 53 & 53 & 69 \\
\hline 3 & Hochimin & 24 & 12 & 12 \\
\hline 4 & Bangkok & 49 & 43 & 49 \\
\hline 5 & Port Klang & 24 & 30 & 24 \\
\hline
\end{tabular}

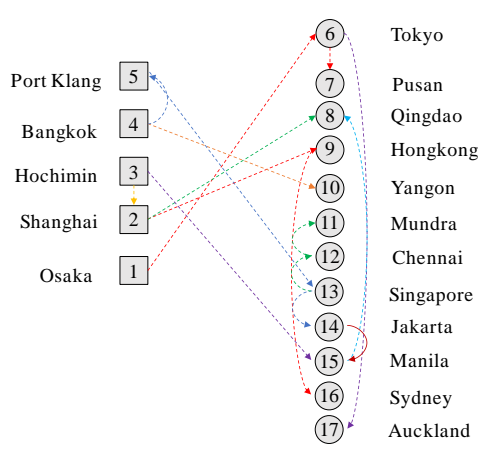

Figure 8. Result of liner shipping network

Operations and Supply Chain Management 14(1) pp. 62 - 72 @ 2021

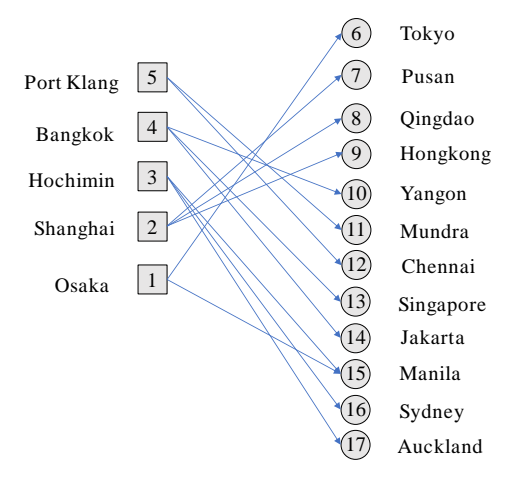

Figure 9. Result of tramp shipping network

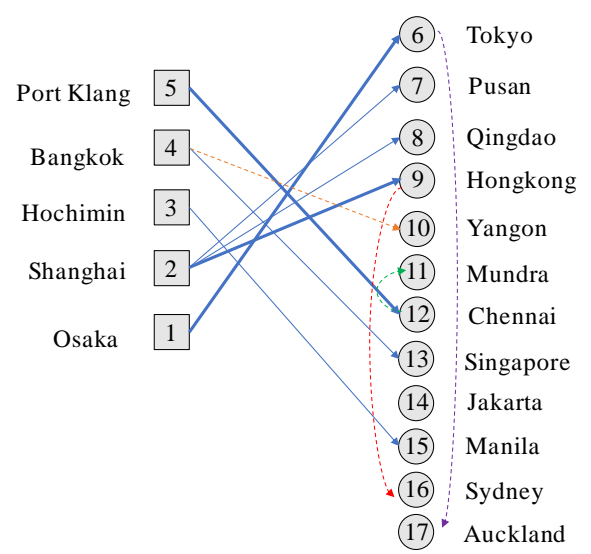

Figure 10. Result of supply flows of mixed shipping

From Table 4, the total cost of mixed shipping is lowest compared with liner and tramp shipping. Table 5 indicates that the production volume allocated to each plant is different among the different scenarios. Table 6 and Figures 8, 9, 10 indicate that the plant from which the demand is sourced is also different among the scenarios. For example, Auckland $(j=17)$ is sourced from the Hochimin plant $(i=3)$ via arc $e=36$ in the tramp mode; whereas, it is sourced from the Osaka plant $(i=1)$ via arc $e=1$ and $e=77$ in the liner and mixed transportation modes.

The total product volume produced in plants changes with transportation modes, which also affects product supplying. The market demand is same for both the liner and tramp shipping network. However, the optimal supply flows change because different shipping modes have different cost functions. For example, the shipping volume in arc $e=16$ is $x_{16}=21$ in tramp mode, which is equals to the demand of Hongkong $(j=9)$. On the other hand, the shipping volume is $x_{16}=37$ in liner mode, which is equals to the demand of Hongkong $(j=9)$ and Sydney $(j=16)$. In the mixed mode, the shipping volume is $x_{16}=37$, the same as in the linear mode. However, in the mixed mode, the shipment is made by the tramp mode, which is cheaper than the liner mode. This option can be only considered in the mixed mode. We also note that Tokyo and Singapore have the highest demand volume, i.e., $d_{j}=21$, and they are sourced from Osaka and Bangkok, respectively. 
Huang, et al.: Incorporating Transportation Mode Decisions into Production-Shipping Planning: Considering Shipping Consolidation Operations and Supply Chain Management 14(1) pp. 62 - 72 (C) 2021

Table 6. Transportation volume from plant to market of mixed shipping (units)

\begin{tabular}{|c|c|c|c|c|c|c|c|c|c|}
\hline \multirow{3}{*}{$\frac{\operatorname{arc}(e)}{1}$} & \multirow{2}{*}{\multicolumn{2}{|c|}{ from $(i)$}} & \multirow{2}{*}{\multicolumn{2}{|c|}{ to $(j)$}} & \multirow{3}{*}{$\begin{array}{c}\text { Tramp } \\
21\end{array}$} & \multirow{3}{*}{$\begin{array}{c}\text { Liner } \\
45 \\
\end{array}$} & \multicolumn{2}{|c|}{ Mixed } & \multirow{3}{*}{$\begin{array}{l}\boldsymbol{d}_{j} \\
21\end{array}$} \\
\hline & & & & & & & \multirow{2}{*}{$\begin{array}{c}\text { Tramp } \\
29\end{array}$} & \multirow{2}{*}{$\frac{\text { Liner }}{0}$} & \\
\hline & 1 & Osaka & 6 & Tokyo & & & & & \\
\hline 10 & 1 & Osaka & 15 & Manila & 12 & 0 & 0 & 0 & 12 \\
\hline 14 & 2 & Shanghai & 7 & Pusan & 16 & 0 & 16 & 0 & 16 \\
\hline 15 & 2 & Shanghai & 8 & Qingdao & 16 & 16 & 16 & 0 & 16 \\
\hline 16 & 2 & Shanghai & 9 & Hong Kong & 21 & 37 & 37 & 0 & 21 \\
\hline 34 & 3 & Hochimin & 15 & Manila & 0 & 12 & 0 & 12 & 12 \\
\hline 35 & 3 & Hochimin & 16 & Sydney & 16 & 0 & 0 & 0 & 16 \\
\hline 36 & 3 & Hochimin & 17 & Auckland & 8 & 0 & 0 & 0 & 8 \\
\hline 41 & 4 & Bangkok & 10 & Yangon & 12 & 12 & 0 & 12 & 12 \\
\hline 44 & 4 & Bangkok & 13 & Singapore & 21 & 0 & 37 & 0 & 21 \\
\hline 45 & 4 & Bangkok & 14 & Jakarta & 16 & 0 & 0 & 0 & 16 \\
\hline 54 & 5 & Port Klang & 11 & Mundra & 12 & 0 & 0 & 0 & 12 \\
\hline 55 & 5 & Port Klang & 12 & Chennai & 12 & 0 & 24 & 0 & 12 \\
\hline 63 & 9 & Hong Kong & 16 & Sydney & 0 & 16 & 0 & 16 & 16 \\
\hline 68 & 4 & Bangkok & 5 & Port Klang & 0 & 31 & 0 & 0 & 0 \\
\hline 69 & 5 & Port Klang & 13 & Singapore & 0 & 61 & 0 & 0 & 21 \\
\hline 70 & 13 & Singapore & 14 & Jakarta & 0 & 16 & 0 & 16 & 16 \\
\hline 73 & 13 & Singapore & 12 & Chennai & 0 & 24 & 0 & 0 & 12 \\
\hline 74 & 12 & Chennai & 11 & Mundra & 0 & 12 & 0 & 12 & 12 \\
\hline 77 & 6 & Tokyo & 17 & Auckland & 0 & 8 & 0 & 8 & 8 \\
\hline
\end{tabular}

Consequently, the total costs change with changes in transportation mode. The mixed shipping mode obtains the lowest costs because of its optimized cargo flow. The case presented indicates that as with all matters of logistics, a onesize-fits-all approach will end in failure in some situations. As shipping volume grows, the tramp shipping may be more appropriate and vice versa. The proposed mixed model can help select the correct shipping mode for each from-to cargo situation, considering transshipment and consolidation to exploit the economies of scale under a given network.

\subsection{Sensitivity Analysis}

In the previous section, we set $\alpha=0.1$ and $\beta=0.2$. $\alpha$ means the coefficient of fixed $\operatorname{cost}, \beta$ means the coefficient of fixed and variable cost in trump shipping. In this section, in order to compare with liner, tramp and mixed shipping, we change the coefficient $\alpha$ and $\beta$ of cost function to see how the ratio of the two cost functions impact the total cost for each scenario. Since $\alpha \leq \beta, 0<\beta<$ 1 (see Figure 7), we set $\alpha=0.03,0.10 .2$, and $\beta \in$ $[0.1,0.9]$, respectively. When the value of $\alpha, \beta$ become bigger, it means the ratio of fixed cost and tramp shipping cost is bigger, so liner shipping appears more competitive. Table 7 summarizes the result of the sensitivity analysis.

If $\alpha=0.03$, and $\beta=0.1$, the mixed shipping cost is same as the tramp shipping cost and much lower than the liner shipping cost. Therefore, the optimal transportation mode is the tramp mode when fixed and variable costs are lower. When tramp costs begin to increase, the mixed mode is obviously more effective from $\alpha=0.03$ and $0.1<\beta<$ 0.9 . However, when $\alpha=0.03$ and $\beta=0.9$, the costs of mixed and liner shipping are the same. This indicates that the optimization network of mixed shipping is same as for the liner shipping network when the fixed and variable costs are higher.
Table 7. Sensitivity analysis with respect to the values of $\alpha$ and $\beta$

\begin{tabular}{|c|c|c|c|c|c|}
\hline Case & $\alpha$ & $\boldsymbol{\beta}$ & $\begin{array}{c}\text { Liner } \\
(\$ 100)\end{array}$ & $\begin{array}{l}\text { Tramp } \\
(\$ 100)\end{array}$ & $\begin{array}{l}\text { Mixed } \\
(\$ 100)\end{array}$ \\
\hline 1 & \multirow{9}{*}{0.03} & 0.1 & \multirow{17}{*}{59.6} & 21.6 & 21.6 \\
\hline 2 & & 0.2 & & 29.3 & 29.3 \\
\hline 3 & & 0.3 & & 37.0 & 36.5 \\
\hline 4 & & 0.4 & & 44.8 & 43.0 \\
\hline 5 & & 0.5 & & 52.5 & 48.8 \\
\hline 6 & & 0.6 & & 60.2 & 53.0 \\
\hline 7 & & 0.7 & & 68.0 & 56.6 \\
\hline 8 & & 0.8 & & 75.7 & 58.7 \\
\hline 9 & & 0.9 & & 83.4 & 59.6 \\
\hline 11 & \multirow{5}{*}{0.1} & 0.2 & & 61.7 & 46.7 \\
\hline 12 & & 0.3 & & 69.4 & 52.1 \\
\hline 13 & & 0.4 & & 77.1 & 55.8 \\
\hline 14 & & 0.5 & & 84.9 & 58.3 \\
\hline 15 & & 0.6 & & 84.9 & 59.6 \\
\hline 16 & \multirow{3}{*}{0.2} & 0.3 & & 115.6 & 57.6 \\
\hline 17 & & 0.4 & & 123.4 & 59.1 \\
\hline 18 & & 0.5 & & 131.1 & 59.6 \\
\hline
\end{tabular}

When the fixed cost of tramp shipping is at a middle level and a higher level and $\alpha=0.1$ and $\alpha=0.2$, it appears that the total costs of the tramp shipping network increase quickly, compared with liner shipping. Thus, liner shipping is recommended in these cases. However, it also shows that the lowest total costs are found in most cases in a production-mixed shipping model, where $0.2 \leq \beta<0.6$ and $0.3 \leq \beta<0.5$.

Consequently, tramp shipping is outstanding when the fixed and variable costs of tramp shipping are cheaper; liner shipping is outstanding when the fixed and variable costs of tramp shipping are higher; the fixed and variable costs of tramp shipping are not consistently cheaper or higher; and mixed shipping - which is proposed in this study - is the optimal mode one and is recommended when making decisions on allocating production. 
Huang, et al.: Incorporating Transportation Mode Decisions into Production-Shipping Planning: Considering Shipping Consolidation

Operations and Supply Chain Management 14(1) pp. $62-72$ @ 2021

\section{CONCLUSIONS}

This paper has proposed a global production-shipping planning model that incorporates the selection of transportation mode that considers the cost function of different transportation modes. The formulation of the model addresses some of the complex issues related to the fixed and variable cost function of tramp shipping and the nonlinear cost function of liner shipping. The results put the focus on production planning that considers tramp, liner, and mixed shipping modes from the shipper's point of view. We applied a piecewise approximation technique with mixed-linear integer programming to linearly approximate and efficiently solve the concave minimization problem with an off-theshelf solver.

In the complexity of globalization and the importance of transportation processes, global manufacturers need to consider complex transportation networks in production planning. Estimating the costs of transportation can be inaccurate and can lead to higher total costs. Selecting a single transportation mode is not enough in the complex global environment. Therefore, this study considers multiple transportation modes and varying unit-transportation costs in production-shipping models. We presented a practical case study motivated by a real-world example. We discussed the differences in production and transportation decisions among three transportation modes (tramp, liner, and mixed). We performed sensitivity analysis to understand how the parameter settings in the cost function influence the choice of transportation modes. The results showed that tramp shipping is outstanding when the fixed and variable costs of tramp shipping are cheaper; liner shipping is outstanding when the fixed and variable costs of tramp shipping are higher; the fixed and variable costs of tramp shipping are not cheaper or higher, and mixed shipping - a hybrid of tramp and liner shipping-is optimal and recommended when allocating production.

The proposed model aims to assist managers make decisions about production allocation, transportation mode selection, shipping contracts by volume with carriers and vessel companies under a given network.

For future work, inventory decision should be extended to simultaneously consider production planning in a multiperiod model to acquire more economies of scale. Another extension of the model relates to a consideration of production costs. The rate of production and transportation cost would change the production allocation and transportation modes. Also, numerical examples could be expanded to land and air transportation in other practical case studies, which is an ongoing extension of this study.

\section{ACKNOWLEDGMENT}

This work was supported by JSPS KAKENHI Grant Number JP20K14987.

\section{REFERENCES}

Andersson, H., Hoff, A., Christiansen, M., Hasle, G., \& Løkketangen, A., (2010). Industrial aspects and literature survey: Combined inventory management and routing. Computers \& Operations Research 37(9),
$1515-1536$.

Archetti, C., Bertazzi, L., Laporte, G., \& Speranza, M. G., (2007). A branch-and-cut algorithm for a vendormanaged inventory-routing problem. Transportation Science 41 (3), 382 - 391.

Armentano, V. A., Shiguemoto, A. L., \& Løkketangen, A., (2011). Tabu search with path relinking for an integrated production-distribution problem. Computers \& Operations Research 38 (8), 1199 - 1209.

Balakrishnan, A., \& Graves, S. C. (1989). A composite algorithm for a concave - cost network flow problem. Networks 19 (2), 175 - 202.

Balakrishnan, A., Magnanti, T. L., \& Mirchandani, P., (1997). Network design. Annotated bibliographies in combinatorial optimization 311- 334.

Boros, E., Lei, L., Zhao, Y., \& Zhong, H., (2008). Scheduling vessels and container-yard operations with conflicting objectives. Annals of Operations Research 161 (1), $149-170$.

Boudia, M., Louly, M. A. O., \& Prins, C., (2007). A reactive GRASP and path relinking for a combined productiondistribution problem. Computers \& Operations Research 34 (11), 3402 - 3419.

Chan, L. M. A., Muriel, A., Shen, Z. J., \& Simchi-Levi, D., (2002). An approximation algorithm for the economic lot sizing model with piece-wise linear cost structures. Operations Research 50, 1058 - 1067.

Chandra, P., (1993). A dynamic distribution model with warehouse and customer replenishment requirements. Journal of the Operational Research Society 44 (7), $681-692$.

Chandra, P., \& Fisher, M. L., (1994). Coordination of production and distribution planning. European Journal of Operational Research, 72(3), 503-517.

Christiansen, M., Fagerholt, K., Nygreen, B., \& Ronen, D., (2007). Maritime transportation. Handbooks in operations research and management science 14, 189 -284 .

Christiansen, M., Fagerholt, K., Nygreen, B., \& Ronen, D., (2013). Ship routing and scheduling in the new millennium. European Journal of Operational Research 228 (3), $467-483$.

Erickson, R. E., Monma, C. L., \& Veinott Jr, A. F., (1987). Send-and-split method for minimum-concave-cost network flows. Mathematics of Operations Research 12 (4), $634-664$.

Fagerholt, K., Christiansen, M., Hvattum, L. M., Johnsen, T. A., \& Vabø, T. J., (2010). A decision support methodology for strategic planning in maritime transportation. Omega 38 (6), 465 - 474.

Fumero, F., \& Vercellis, C., (1999). Synchronized development of production, inventory, and distribution schedules. Transportation Science 33 (3), 330 - 340.

Gatica, R. A., \& Miranda, P. A., (2011). Special issue on Latin-American research: A time based discretization approach for ship routing and scheduling with variable speed. Networks and Spatial Economics 11 (3), 465 485.

Gelareh, S., \& Meng, Q., (2010). A novel modeling approach for the fleet deployment problem within a short-term planning horizon. Transportation Research Part E: 
Logistics and Transportation Review 46 (1), 76 - 89.

Gelareh, S., Nickel, S., \& Pisinger, D., (2010). Liner shipping hub network design in a competitive environment. Transportation Research Part E: Logistics and Transportation Review 46 (6), 991 - 1004.

Hoff, A., Andersson, H., Christiansen, M., Hasle, G., \& Løkketangen, A., (2010). Industrial aspects and literature survey: Fleet composition and routing. Computers \& Operations Research 37 (12), 2041 2061.

Hsu, C. I., \& Hsieh, Y. P., (2007). Routing, ship size, and sailing frequency decision-making for a maritime huband-spoke container network. Mathematical and Computer Modelling 45 (7-8), 899 - 916.

Jetlund, A. S., \& Karimi, I. A., (2004). Improving the logistics of multi-compartment chemical tankers. Computers \& Chemical Engineering 28 (8), 1267 1283.

Karlaftis, M. G., Kepaptsoglou, K., \& Sambracos, E., (2009). Containership routing with time deadlines and simultaneous deliveries and pick-ups. Transportation Research Part E: Logistics and Transportation Review 45 (1), $210-221$.

Kim, D., \& Pardalos, P. M., (2000). Dynamic slope scaling and trust interval techniques for solving concave piecewise linear network flow problems. Networks: An International Journal 35 (3), 216 - 222.

Korsvik, J. E., Fagerholt, K., \& Laporte, G., (2010). A tabu search heuristic for ship routing and scheduling. Journal of the Operational Research Society 61 (4), $594-603$.

Lagoudis, I. N., Fragkos, S. N., \& Litinas, N. A., (2009). Estimating optimum container and vessel fleet sizes in a cyclic liner service using a holistic approach. International Journal of Shipping and Transport Logistics 2 (1), $4-21$.

Lakhal, S. (2018). A Study on the Maritime Transport Network Design under Different Charter Rates: The Case of LNG Transport between Qatar and Turkey. Operations and Supply Chain Management: An International Journal 11(1), 13-25.

Lei, L., Fan, C., Boile, M., \& Theofanis, S., (2008). Collaborative vs. non-collaborative container-vessel scheduling. Transportation Research Part E: Logistics and Transportation Review 44 (3), 504 - 520.

Lin, D. Y., \& Liu, H. Y., (2011). Combined ship allocation, routing and freight assignment in tramp shipping. Transportation Research Part E: Logistics and Transportation Review 47 (4), 414 - 431.

Magnanti, T. L., \& Wong, R. T., (1984). Network design and transportation planning: Models and algorithms. Transportation science 18 (1), $1-55$.

Mahey, P., \& Souza, M. C. D., (2017). Multicommodity network flows with nonconvex arc costs. Pesquisa Operacional 37 (3), $571-595$.

Malliappi, F., Bennell, J. A., \& Potts, C. N., (2011). A variable neighborhood search heuristic for tramp ship scheduling. In International Conference on Computational Logistics (pp. 273-285). Springer, Berlin, Heidelberg.
Meng, Q., \& Wang, S., (2011). Liner shipping service network design with empty container repositioning. Transportation Research Part E: Logistics and Transportation Review 47 (5), 695 - 708.

Muriel, A., \& Munshi, F. N., (2004). Capacitated multicommodity network flow problems with piecewise linear concave costs. IIE Transactions, 36 (7), $683-696$

Ng, A. K. Y., \& Kee, J. K., (2008). The optimal ship sizes of container liner feeder services in Southeast Asia: a ship operator's perspective. Maritime Policy \& Management 35 (4), $353-376$.

Papageorgiou, D. J., Cheon, M. S., Harwood, S., Trespalacios, F., \& Nemhauser, G. L., (2018). Recent progress using matheuristics for strategic maritime inventory routing. In Modeling, Computing and Data Handling Methodologies for Maritime Transportation (pp. 59-94). Springer, Cham.

Powell, B. J., \& Perkins, A. N., (1997). Fleet deployment optimization for liner shipping: An integer programming model. Maritime Policy and Management 24 (2), 183 - 192.

Reinhardt, L. B., \& Pisinger, D., (2012). A branch and cut algorithm for the container shipping network design problem. Flexible Services and Manufacturing Journal 24 (3), $349-374$.

Ronen, D., (1993). Ship scheduling: The last decade. European Journal of Operational Research, 71 (3), 325 $-333$.

Ruokokoski, M., Solyali, O. G. U. Z., Cordeau, J. F., Jans, R., \& Süral, H., (2010). Efficient formulations and a branch-and-cut algorithm for a production-routing problem. GERAD Technical Report G-2010-66.

Sherali, H. D., \& Al-Yakoob, S. M., (2006a). Determining an optimal fleet mix and schedules: Part I-single source and destination. In Integer Programming (pp. 153-182). CRC Press

Sherali, H. D., \& Al-Yakoob, S. M., (2006b). Determining an optimal fleet mix and schedules: Part II-multiple sources and destinations, and the option of leasing transshipment depots. In Integer Programming (pp. 183-210). CRC Press.

Shu, J. (2010)., An efficient greedy heuristic for warehouseretailer network design optimization. Transportation Science 44 (2), 183 - 192.

Solyalı, O., \& Süral, H., (2009). A relaxation based solution approach for the inventory control and vehicle routing problem in vendor managed systems. In Modeling, computation and Optimization (pp. 171-189).

Song, J. H., \& Furman, K. C., (2013). A maritime inventory routing problem: Practical approach. Computers \& Operations Research 40(3), $657-665$.

Teo, C. P., \& Shu, J., (2004). Warehouse-retailer network design problem. Operations Research 52 (3), $396-408$.

Tuy, H., (1964). Concave programming under linear constraints. In Soviet Mathematics Doklady (Vol. 5, pp. 1437-1440).

Vanteddu, G., \& Nicholls, G. (2019). Supply Chain Network Design and Tactical Planning in the Dimension Stone Industry. Operations and Supply Chain Management: 
Huang, et al.: Incorporating Transportation Mode Decisions into Production-Shipping Planning: Considering Shipping Consolidation

Operations and Supply Chain Management 14(1) pp. $62-72$ @ 2021

An International Journal 13(4), 320-335.

Wang, X., Norstad, I., Fagerholt, K., \& Christiansen, M., (2019). Green Tramp Shipping Routing and Scheduling: Effects of Market-Based Measures on CO 2 Reduction. In Sustainable Shipping (pp. 285-305). Springer, Cham.

Wang, X., Norstad, I., Fagerholt, K., \& Christiansen, M., (2019). Green Tramp Shipping Routing and Scheduling: Effects of Market-Based Measures on CO 2 Reduction. In Sustainable Shipping (pp. 285-305). Springer, Cham.

Ward, J. A., (1999). Minimum-aggregate-concave-cost multicommodity flows in strong-series-parallel networks. Mathematics of Operations Research 24 (1), $106-129$.

Wen, M., Pacino, D., Kontovas, C. A., \& Psaraftis, H. N.,
(2017). A multiple ship routing and speed optimization problem under time, cost and environmental objectives. Transportation Research Part D: Transport and Environment 52, 303 - 321.

Zangwill, W. I., (1968). Minimum concave cost flows in certain networks. Management Science 14 (7), 429 450.

Zeng, Q., \& Yang, Z., (2007). Model integrating fleet design and ship routing problems for coal shipping. In International Conference on Computational Science (pp. 1000-1003). Springer, Berlin, Heidelberg.

Zhang, C., Nemhauser, G., Sokol, J., Cheon, M. S., \& Keha, A., (2018). Flexible solutions to maritime inventory routing problems with delivery time windows. Computers \& Operations Research 89, 153 - 162.

Qian Huang is a researcher at Waseda Research Institute for Science and Engineering, Waseda University in Japan. Her research interests include production planning, design of global supply chain and optimization of production and logistics systems.

Shunichi Ohmori $(\mathrm{PhD})$ is an associate professor at Department of Industrial \& System Engineering, Waseda University in Japan, and a researcher at Institute of Global Production \& Logistics at Waseda University, and a researcher at Data Science Institute at Waseda University. He received the master and Ph.D degree in engineering at Waseda University. His research interest lies in operations research and supply chain management.

Kazuho Yoshimoto (Dr.Engg) is a professor at Department of Industrial \& System Engineering at Waseda University in Japan, and a head of Institute of Global Production \& Logistics at Waseda University. He received the master and Ph.D degree in engineering at Waseda University. His research interest lies in facility and logistics design. 